\title{
Problem Analysis and Recommendations of CPU Contents in Korean Middle School Informatics Textbooks
}

\author{
Sangwook Lee ${ }^{\dagger} \cdot$ Taeweon Suh $^{++}$
}

\begin{abstract}
The School Curriculum amend in 2007 mandates the contents from which students can learn the principles and concepts of computer science. Computer Science is one of the most rapidly changing subjects, and the Informatics textbook should accurately explain the basic principles and concepts based on the latest technology. However, we found that the middle school textbooks in circulation lack accuracy and consistency in describing CPU. This paper attempted to discover the root-cause of the fallacy and suggest timely and appropriate explanation based on the historical and technical analysis. According to our study, it is appropriate to state that CPU is composed of datapath and control unit. The Datapath performs operations on data and holds data temporarily, and it is composed of the hardware components such as memory, register, ALU and adder. The Control unit decides the operation types of datapath elements, main memory and I/O devices. Nevertheless, considering the technological literacy of middle school students, we suggest the terms, 'arithmetic part' and 'control part' instead of datapath and control unit.
\end{abstract}

Keywords: Korean Informatics Textbook, CPU

\section{중학교 정보 교과서에 제시된 중앙처리장치 내용 문제점 분석 및 개선 방안}

이 상 욱 ${ }^{+}$서 태 원 ${ }^{++}$

요 약

2007년 개정 교육과정에서 컴퓨터 교육은 컴퓨터 과학의 원리와 개념을 배울 수 있는 내용을 강화하였다. 따라서 정보 교과서는 빠르게 발 전하고 있는 컴퓨터 과학의 최신 흐름을 정확하고 일관되게 반영할 필요가 있다. 하지만 현재 중학교 정보 교과서에 제시된 중앙 처리 장치의 구성 요소에 대한 내용은 교과서마다 차이를 보여 정확성과 일관성이 결여되어 있다. 본 연구는 컴퓨터 구조 및 동작의 역사적, 기술적 접근을 통해 교과서 내용의 오류를 파악하고 개선 방안을 제시하였다. 연구 결과, 현재 컴퓨터 시스템의 중앙처리장치는 데이터패스와 제어 장치로 구 성되었다고 기술하는 것이 바람직하다. 데이터패스는 명령어의 수행에 따라 데이터의 연산 또는 데이터를 일시적으로 저장하는 기능을 수행하 며 메모리, 레지스터, 연산 장치, 가산기 등으로 구성된다. 제어 장치는 명령어의 수행에 따라 데이터패스, 주기억 장치, 입출력 장치 등의 동작 유형을 결정한다. 하지만 어려운 전문 용어의 사용이 인지 발달 수준이 낮은 학습자의 학습을 저해할 수 있기 때문에 본 연구에서는 데이터패 스와 제어 장치 대신 '연산부'와 '제어부'라는 표현을 사용할 것을 제안한다.

키워드 : 정보 교과서, 중앙처리장치

\section{1. 서 론}

우리나라 국가 교육과정에서 컴퓨터 교육은 1969년 문교 부령 제251호에 따른 고등학교 교육과정의 '산업 일반' 과목 에 컴퓨터 관련 내용이 포함된 것이 시초이다. 이후 1971년

† 준 회 원 : 고려대학교 컴퓨터교육과 석사과정

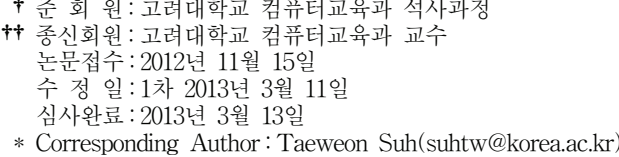

* Corresponding Author: Taeweon Suh(suhtw@korea.ac.kr)

문교부령 제 286 호로 공포된 실업계 고등학교 교육과정에서 '전자 계산 일반'을 포함하여 5종의 컴퓨터 관련 과목이 처 음으로 신설되었다[1]. 1974년 문교부령 제350호에서는 인문 계 고등학교 교육과정의 '기술' 과목에 컴퓨터 관련 영역이 포함되었다. 이것은 전문 계열 고등학교를 중심으로 전문 정보 처리 기능 인력의 양성을 목적으로 시작된 컴퓨터 교 육이 일반 교육으로 그 개념이 변화된 것을 의미한다. 일반 계 고등학교 최초의 컴퓨터 관련 과목은 1988년 문교부 고 시 제88-7호에 따라 기술- 가정 교과의 선택 과목으로 도입 
된 '정보 산업’이다[2]. 중학교에서는 1992년 교육부 고시 제 1992-11호에 따라 처음으로 컴퓨터 관련 과목인 '컴퓨터'가 신설되어 본격적인 정보화 시대를 대비한 컴퓨터 교육 체제 로 발전하였다. 1992년에 고시된 제6차 교육과정에서 컴퓨 터 교육은 응용 소프트웨어를 이용하여 일상생활의 당면 문 제 해결에 컴퓨터를 주요 도구로 활용할 수 있는 능력을 기 르도록 하였다. 1997년에 고시된 제7차 교육과정에서도 교 과의 목표를 정보 사회에 필요한 기본 소양 함양에 두었고 모든 교과의 학습 활동에 정보 기술을 도구로 사용하도록 확대되었다.

정보화 시대는 컴퓨터를 도구적으로 활용하는 것도 중요 하지만 다양한 지식과 정보가 융합되어 발전하는 지식정보 사회의 복잡한 문제들을 해결하기 위해서는 컴퓨터 과학의 원리를 이해하고 창의적, 논리적으로 사고하는 능력을 기르 는 것이 더욱 중요하다. 이러한 이유로 2007년 개정 교육과 정에서는 중학교와 일반계 고등학교의 컴퓨터 관련 과목 명 칭을 ‘정보'로 통일하고 컴퓨터의 단순 도구적 활용 교육보 다는 컴퓨터 원리, 문제 해결 방법, 정보 윤리 교육 등을 강 화하였다. 컴퓨터 과학의 기본 원리를 바탕으로 정보 사회 를 올바로 이해하고 미래의 지식정보 사회에서 요구되는 창 의적 문제 해결력과 논리적 의사 결정력을 기를 수 있는 과 학으로서의 정보 교육 체계를 마련한 것이다[3, 4].

정보 교육과정의 목표를 실현하기 위해서는 수업 설계, 교 육 평가 등 모든 교육 활동의 근간이 되는 교과서의 내용이 무엇보다 중요하다. 정보 교과서는 컴퓨터 과학 분야의 기초 지식을 바르게 전달하고 새로운 지식을 창조해 낼 수 있는 가치를 지녀야 한다. 정보 교과서는 컴퓨터 과학의 원리와 개념을 정확하게 설명해야 하고 빠르고 눈부시게 발전하고 있는 컴퓨터 과학 기술의 변화 또한 시기적절하게 반영해야 한다. 하지만 현재의 정보 교과서에 제시된 '컴퓨터의 구성과 동작' 영역에는 컴퓨터의 급속한 변화를 제대로 반영하지 못 하는 내용이 포함되어 있다. 대표적인 예로 중앙처리장치 (CPU: Central Processor Unit)에 대한 내용이다. 2007년 개 정 교육과정에 따른 8 종의 중학교 정보 교과서[5-12]를 분석 한 결과 중앙처리장치의 구성 요소에 대한 내용이 포함된 5 종의 교과서 중 4 종의 교과서가 중앙처리장치를 '제어 장치' 와 '연산 장치'로 구분하였고, 1 종의 교과서가 '제어 장치', ‘연산 장치', ‘레지스터'로 구분하였다. 중앙처리장치의 구성에 대한 이러한 내용들은 현재 대부분의 $\mathrm{PC}$, 서버, 임베디드 시 스템 등에서 사용되고 있는 중앙처리장치의 구조를 바르게 설명하고 있지 못할 뿐 아니라 교과서별 상이한 내용으로 인 해 학습자에게 혼란을 유발할 소지가 있다.

본 연구에서는 대부분의 대학에서 컴퓨터 구조 과목의 전 공 교재로 사용되고 있는 전문 서적[13]을 포함한 4종의 컴 퓨터 전문 서적[13-16]과 8종의 중학교 정보 교과서[5-12]에 제시된 중앙처리장치 관련 내용을 비교 분석하여 교과서가 가지고 있는 내용상의 문제점을 파악하였다. 또한 컴퓨터 구조 및 동작에 대한 역사적, 기술적 접근을 통하여 중앙처 리장치에 대한 바람직한 교과 내용을 제시하였다.

\section{2. 관련 연구}

강오한[17]은 2007년 개정 교육과정에 따른 중학교 정보1 교과서를 분석하였고 설문조사를 통해 정보1 교과서의 조기 정착 방안을 모색하였다. 설문 항목은 정보1 교과서의 만족 도와 향후 교사들을 위해 지원이 필요한 내용을 조사하는 것으로 구성되었다. 교과서에 대한 설문의 영역은 교육과정 의 준수, 내용의 선정 및 조직, 창의성, 교수·학습 방법 및 평가, 내용의 정확성, 표현표기 및 편집, 교과서 만족도 등이 다. 설문 영역 중에서 긍정적인 응답률이 가장 높은 것은 ‘교육과정의 준수'로 95\%를 나타냈고 부정적인 응답률이 가 장 높은 설문 영역은 '내용의 선정 및 조직'으로 $13 \%$ 를 나 타냈다. 또한 교과서에 대한 전반적인 만족도에서는 긍정적 인 응답은 $76 \%$ 를 차지하였고 부정적인 응답은 $2 \%$ 로 매우 낮게 나타났다.

이상욱[18]은 고등학교 정보 교과서에 제시된 기억 장치 관련 내용에 대한 오류의 원인을 파악하고 개선 방안을 제 시하였다. 정보 교과서는 주기억 장치를 RAM과 ROM으로 구분하였고, 가상 메모리를 주기억 장치의 용량보다 큰 프 로그램을 실행하기 위해 보조기억 장치의 일부를 주기억 장 치처럼 사용하는 것으로 설명하였다. 관련 연구에서는 실행 중인 프로그램과 실행에 필요한 데이터를 일시적으로 저장 하는 주기억 장치를 현재의 반도체 기술로는 RAM으로 구 현하고 있기 때문에 주기억 장치의 종류에 $\mathrm{ROM}$ 을 포함시 키는 것은 적절하지 않다는 것을 메모리 계층 구조를 통하 여 보여주었다. 그리고 가상 메모리는 주기억 장치를 보조 기억 장치의 캐시로 활용하는 기법으로 보는 것이 적절하며, 교과서의 내용 중 보조기억 장치의 일부를 주기억 장치로 사용한다는 가상 메모리에 대한 설명은 스왑 스페이스에 대 한 내용이라고 하였다. 또한 대용량의 주기억장치가 장착되 어 있는 현재의 컴퓨터 시스템에서 가상 메모리를 사용하는 이유로, 주기억 장치보다 큰 프로그램을 실행할 수 있다는 점보다 다수의 프로그램이 효과적으로 주기억 장치를 공유 할 수 있다는 점이 더 강조되는 것이 바람직하다고 하였다.

이상욱[19]은 2007년 개정 교육과정에 따른 중학교 정보 교과서 및 정보 분야 국가기술자격 검정의 정보 기기 영역 내용에 대한 문제점을 연구하였다. 연구 결과, 중앙처리장치 의 구성 요소를 정보 교과서, 정보 분야 국가기술자격 검정 수험서, 그리고 컴퓨터 전문 서적에서 서로 다르게 구분하 고 있었다. 또한 교과서와 국가기술자격 검정 수험서에 제 시된 주기억 장치와 가상 메모리에 대한 내용이 컴퓨터 전 문 서적과 서로 다름을 확인하였다.

본 연구는 2007년 개정 교육과정에 의해 구성된 정보 교 과서가 연구의 대상이라는 점에서 관련 연구와 공통점이 있 다. 하지만, 정보 교과 내용의 오류를 찾아 그 원인을 분석 하고 개선 방안을 제시한다는 점에서는 설문을 통해 교과 내용의 전반적인 평가를 시도한 강오한[17]과 차이가 있다. 또한 중학교 정보 교과서의 중앙처리장치에 대한 내용을 연 구한다는 점에서는 고등학교 정보 교과서의 주기억장치와 가상메모리를 분석한 이상욱[18]과 차이를 보인다. 그리고 
Table 1. CPU descriptions in Informatics textbooks of Korean middle schools

\begin{tabular}{|c|c|}
\hline Textbooks & $\mathrm{CPU}$ \\
\hline $\begin{array}{l}\text { Kumsung Pub. } \\
\text { Kim(2011) }\end{array}$ & $\begin{array}{l}\text { - 중앙 처리 장치 }(\mathrm{CPU}) \text { 는 사람의 두뇌와 같은 역할을 하는 가장 중요한 구성 요소로서, 제어 장치와 연산 장 } \\
\text { 치로 구성된다. } \\
\text { - 제어 장치는 프로그램의 명령에 따라 컴퓨터의 각 구성 장치가 적절하게 동작하도록 지시하고, 연산 장치는 } \\
\text { 프로그램의 명령을 실행하여 입력된 자료를 원하는 형태의 정보로 변환하는 일을 한다. }\end{array}$ \\
\hline $\begin{array}{l}\text { Doosan Dong-- } \\
\text { Lee(2011) }\end{array}$ & $\begin{array}{l}\text { - 컴퓨터의 두뇌에 해당하는 것으로 각종 명령어를 체계적으로 수행하는 등 제어·연산 기능을 담당하는 장치 } \\
\text { 이며, 보통 CPU(Central Processing Unit)라고 한다. }\end{array}$ \\
\hline & $\begin{array}{l}\text { - 중앙 처리 장치는 컴퓨터의 가장 중요한 부분으로 사용자의 명령을 처리하고 실행한다. 중앙 처리 장치는 } \\
\text { 컴퓨터 장치의 동작을 제어하고 연산 기능을 수행하는 장치이다. }\end{array}$ \\
\hline $\begin{array}{l}\text { Samyang Media } \\
\text { Jung(2011) }\end{array}$ & $\begin{array}{l}\text { - 중앙 처리 장치는 사람의 두뇌에 해당하는 매우 중요한 부분이다. 중앙 처리 장치는 입력 장치를 통해 입력 } \\
\text { 된 내용을 목적에 맞도록 해석하고 처리하여 결과를 만들어 내는 역할을 하는 것으로, 연산 장치와 제어 장 } \\
\text { 치로 나눌 수 있다. } \\
\text { - 연산 장치는 숫자 계산, 문자나 기호의 비교 - 판단 등과 같은 프로그램 명령을 실제로 수행하고, 제어 장치 } \\
\text { 는 자료를 목적에 맞게 처리하기 위하여 각 장치에 신호를 보내어 작동 순서를 지시하는 역할을 한다. }\end{array}$ \\
\hline $\begin{array}{r}\text { Saengne } \\
\text { Hong }\end{array}$ & $\begin{array}{l}\text { - 중앙 처리 장치는 프로그램의 명령을 수행한다. 중앙 처리 장치는 컴퓨터의 두뇌로서 처리 속도가 가장 큰 } \\
\text { 영향을 끼친다. 하드웨어를 구성하는 모든 장치를 관리하고 데이터에 대한 계산과 비교 연산을 담당한다. }\end{array}$ \\
\hline $\begin{array}{l}\text { Youngjin Media } \\
\text { Kang(2011) }\end{array}$ & $\begin{array}{l}\text { - 컴퓨터 전체의 동작을 제어하고 사용자로부터 다양한 자료를 입력반아 처리를 한 후 원하는 정보를 출력해 } \\
\text { 주는 일련의 과정을 제어하고 조정하는 역할을 수행하는 장치가 중앙 처리 장치이다. } \\
\text { - 중앙 처리 장치는 연산, 비교, 판단을 수행하는 연산 장치와 명령어를 해석하고 실행하는 제어 장치로 구성 } \\
\text { 된다. }\end{array}$ \\
\hline $\begin{array}{l}\text { Jihaksa Pub. } \\
\text { Kang(2011) }\end{array}$ & $\begin{array}{l}\text { - 중앙 처리 장치는 사람의 두뇌에 해당하는 것으로, 제어 장치와 연산 장치를 하나의 반도체 칩으로 구성한 } \\
\text { 것이다. } \\
\text { - 제어 장치는 프로그램의 명령에 따라 관련 장치에 필요한 동작을 하도록 지시하는 역할을 하며, 연산 장치 } \\
\text { 는 연산을 수행하는 장치로 실제 프로그맴의 명령을 실행한다. }\end{array}$ \\
\hline $\begin{array}{l}\text { Chunjae Education } \\
\text { Kim(2011) }\end{array}$ & $\begin{array}{l}\text { - 컴퓨터의 두뇌에 해당하는 부분으로 컴퓨터 시스템을 관리하는 제어 장치, 연산을 수행하는 연산 장치, 일시 } \\
\text { 적으로 데이터를 저장하는 레지스터로 구성된다. }\end{array}$ \\
\hline
\end{tabular}

정보 교과서의 중앙처리장치에 대한 심도 있는 문제점 분석 과 함께 개선 방안을 제시한다는 점에서는 정보기기 영역 내용의 문제점만을 제기한 이상욱[19]과 차이가 있다.

\section{3. 중앙처리장치 구성 요소 비교}

\section{1 교과서의 중앙처리장치 내용}

정보 교과에서 중앙처리장치 관련 내용은 중학교 정보 교 과서의 '컴퓨터의 구성과 동작' 영역에 포함되어 있다. Table 1은 중학교 정보 교과서의 중앙처리장치에 대한 내용 을 요약한 것이다.

8 종의 교과서 중 4 종의 교과서 $[5,8,10,11]$ 에서 중앙처리 장치의 구성 요소를 '제어 장치'와 '연산 장치'로 구분하고 있으며 1종의 교과서[12]에서 '제어 장치', '연산 장치', 그리 고 ‘레지스터'로 구분하고 있다. 여기서 연산 장치는 연산을 수행하는 유닛인 산술 논리 장치(ALU: Arithmetic Logic Unit)를 의미하고 레지스터는 명령어의 수행에 필요한 데이 터를 일시적으로 저장하는 중앙처리장치 내부의 기억 공간 을 의미한다. 나머지 3 종의 교과서 $[6,7,9]$ 는 중앙처리장치 의 구성 요소에 대하여 직접 언급하지는 않고 역할 면에서 제어와 연산의 기능을 담당한다고 설명한다.

교과서는 정확한 지식 내용을 담아야 하고 학습자의 수준 에 맞게 정제된 내용을 정선해서 담아야 한다는 점에서 현 재의 교과서는 다음과 같은 문제점을 가지고 있다.
- 중앙처리장치의 구성 요소에 대한 내용이 교과서에 따 라 다름

- 중앙처리장치의 구성 요소들 간의 유기적인 관계에 대 한 설명이 부족

\section{2 전문 서적의 중앙처리장치 내용}

Table 2는 컴퓨터 구조 분야의 대표적인 전문 서적에서 설명하고 있는 중앙처리장치 관련 내용을 요약한 것이다. 특히 Table 2는 컴퓨터의 발전에 따라 중앙처리장치의 구성 요소에 대한 역사적인 변화를 보여준다.

Hayes(1978)[13]는 중앙처리장치를 데이터 처리와 제어의 두 부분으로 구분하고, 데이터 처리 부분을 '산술 논리 장 치', 제어 부분을 ‘프로그램 제어 장치’로 설명하였다. 20년 후 개정되어 출간된 Hayes(1998)[15]는 중앙처리장치를 특 정한 명령어를 수행하기 위한 논리 회로를 포함하고 있는 장치로서, '제어 장치(control unit)'와 '데이터패스(datapath)' 로 나누어진다고 기술하였다. 제어 장치는 메모리에 저장된 명령어와 데이터의 주소를 생성하고, 데이터패스는 명령어 를 수행하는 산술 논리 회로와 일시적으로 데이터를 저장하 는 레지스터를 포함한다고 설명하였다.

Mano(1993)[14]는 중앙처리장치를 컴퓨터 시스템에서 대 부분의 데이터를 처리하는 장치로 설명하고 있으며 Fig. 1 과 같이 '레지스터', '산술 논리 장치', 그리고 '제어 장치'로 구분하고 있다. 
Table 2. CPU descriptions in university textbooks on computer architecture

\begin{tabular}{|c|c|}
\hline Technical books & $\mathrm{CPU}$ \\
\hline $\begin{array}{l}\text { Computer Architecture } \\
\text { and Organization } \\
\text { Hayes(1978) }\end{array}$ & $\begin{array}{l}\text { - CPUs generally exhibit a clear-cut division into data processing and control parts; the former is called } \\
\text { the arithmetic-logic unit (ALU) or execution unit; the latter is called the program control unit. }\end{array}$ \\
\hline $\begin{array}{c}\text { Computer System } \\
\text { Architecture } \\
\text { Mano(1993) }\end{array}$ & $\begin{array}{l}\text { - The part of the computer that performs the bulk of data-processing operations is called the central } \\
\text { processing unit and is referred to as the CPU. } \\
\text { - The CPU is made up of three major parts: register set, ALU, and control unit. } \\
\text { - The register set stores intermediate data used during the execution of the instructions. } \\
\text { - The arithmetic logic unit (ALU) performs the required microoperations for executing the instructions. } \\
\text { - The control unit supervises the transfer of information among the registers and instructs the ALU as to } \\
\text { which operation to perform. }\end{array}$ \\
\hline $\begin{array}{c}\text { Computer Architecture } \\
\text { and Organization } \\
\text { Hayes(1998) }\end{array}$ & $\begin{array}{l}\text { - The CPU contains the logic needed to execute its particular instruction set and is divided into datapath } \\
\text { and control units. } \\
\text { - The control part generates the addresses of instructions and data stored in external memory. } \\
\text { - The CPU's datapath has the arithmetic-logic circuits that execute most instructions; it also has a set of } \\
\text { registers for temporary data storage. }\end{array}$ \\
\hline $\begin{array}{c}\text { Compute Organization } \\
\text { and Design } \\
\text { Patterson(2008) }\end{array}$ & $\begin{array}{l}\text { - The processor logically comprises two main components: datapath and control, the respective brawn and } \\
\text { brain of the processor. } \\
\text { - Datapath : The component of the processor that performs arithmetic operations. } \\
\text { - Datapath element : A unit used to operate on or hold data within a processor. In the MIPS } \\
\text { implementation, the datapath elements include the instruction and data memories, the register file, the } \\
\text { ALU, and adders. } \\
\text { - Control : The component of the processor that commands the datapath, memory, and I/O devices } \\
\text { according to the instructions of the program. }\end{array}$ \\
\hline
\end{tabular}

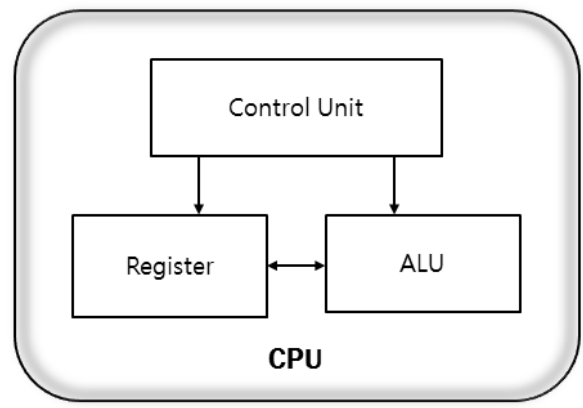

Fig. 1. Simplified CPU schematic in Mano's book (1993)

Patterson(2008)[16]은 중앙처리장치(프로세서)를 논리적 으로 '데이터패스'와 '제어 장치'의 두 가지 요소로 구분하고 있다. 데이터패스는 명령어의 수행에 따라 데이터의 연산 또는 데이터를 가지고 있는 역할을 하는 구성 요소로서 메 모리, 레지스터, $\mathrm{ALU}$, 가산기 등을 포함한다고 설명하고 있 다. 제어 장치는 명령어의 수행에 따라 데이터패스, 주기억 장치, 입출력 장치 등의 동작을 지시하는 구성 요소로 설명 하고 있다.

\section{3 교과서와 전문 서적 비교 분석}

언급한 바와 같이 5 종의 중학교 정보 교과서 중에서 4 종 $[5,8,10,11]$ 은 중앙처리장치를 제어 장치와 연산 장치로 구분하고 있다. 이는 1978년에 출간된 Hayes에 기반하고 있 는 것으로 추측된다. 또한 나머지 1종[12]은 제어 장치, 연산 장치, 레지스터로 구분하고 있는데, 이는 1993년에 출간된
Mano의 설명을 따르고 있는 것으로 판단된다. 이러한 사실 은 현재의 정보 교과서가 급속도로 발전하고 있는 컴퓨터 하드웨어 기술을 제대로 반영하지 못하고 있다는 것을 보여 준다. 초판 발행 20년 후 개정 발행된 Hayes (1998)와 최근 에 출간된 Patterson(2008)이 중앙처리장치를 설명하기 위해 기존의 전문 서적과는 다르게 중앙처리장치의 구성 요소를 데이터패스와 제어 장치로 구분하고 있다는 것이 이러한 점 을 잘 뒷받침 해주고 있다.

중앙처리장치의 구성 요소에 대한 내용이 전문 서적에서 변화하게 된 원인을 역사적 관점에서 파악하기 위해 초기 컴퓨터 시스템에서 사용된 중앙처리장치와 현재의 컴퓨터 시스템에서 사용되고 있는 중앙처리장치의 구조에 대하여 분석하였다. 현대 컴퓨터 시스템에서 사용하고 있는 프로그 램 내장 방식(stored-program)을 최초로 제안한 사람은 프 린스턴 대학과 프린스턴 고등연구소(IAS: Institute for Advanced Study)의 수학자였던 폰노이만이다. 그가 설계한 컴퓨터 시스템 구조를 폰노이만 구조라 하며 이에 따라 최 초로 만들어진 컴퓨터를 폰노이만 컴퓨터(또는 IAS 컴퓨터) 라 부른다. Fig. 2는 폰노이만 컴퓨터의 중앙처리장치 구조 를 나타낸 것이다. 폰노이만 컴퓨터의 중앙처리장치는 산술 논리 장치(ALU: Arithmetic Logic Unit)와 프로그램 제어 장치(PCU: Program Control Unit)로 이루어져 있다. 이는 Hayes(1978)가 설명한 중앙처리장치의 구성 요소와 일치한 다. 그러나 20년 후 Hayes(1998)는 중앙처리장치를 데이터 패스와 제어 장치로 구분하였다. 중앙처리장치의 구성 요소 를 설명하면서 20년 전에 사용한 '산술 논리 장치'라는 용어 대신 '데이터패스'를 사용한 것이다. 이러한 변화는 중앙처리 


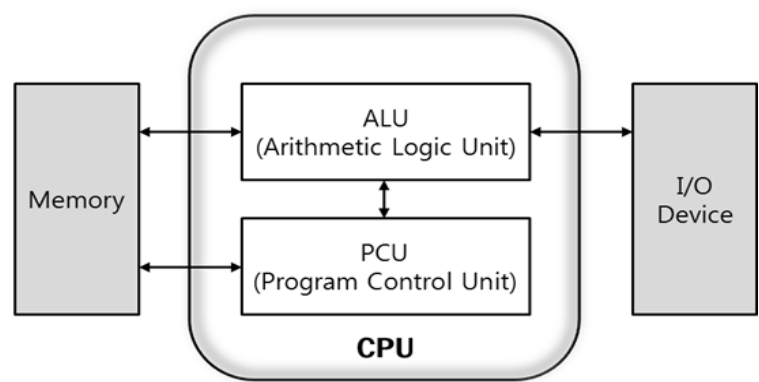

Fig. 2. CPU schematic diagram in Von Neumann computer

장치가 발전함에 따라 기존에 사용했던 '산술 논리 장치 (ALU)'라는 용어가 더 이상 제어 장치를 제외한 나머지 부 분을 표현하는 용어로 적절하지 않게 되었기 때문으로 판단 된다.

Mano(1993)는 Hayes(1978)가 제안한 중앙처리장치의 구 성 요소에 Fig. 1과 같이 레지스터를 추가하고 있다. 레지스 터는 명령어를 처리하기 위해 필요한 데이터를 중앙처리장 치 내부에 임시로 저장하는데 사용된다. 컴퓨터 시스템이 발전하면서 레지스터의 중요성이 점점 높아졌기 때문에 Mano(1993)는 중앙처리장치의 구성 요소에 레지스터를 포 함시킨 것으로 보인다. 레지스터는 중앙처리장치와 메모리 간 발전 속도의 차이 때문에 캐시와 더불어 컴퓨터 시스템 의 중요한 구성 요소가 되었다. 무어의 법칙(Moore's law)에 따라 중앙처리장치는 18 개월 마다 2 배로 성능이 향상되고 있지만 메모리의 발전 속도는 상대적으로 느려 평균적으로 10 년 마다 2 배로 성능이 향상되고 있다. 따라서 접근 속도
가 느린 주기억 장치의 사용을 최소로 줄이고 중앙처리장치 의 효율을 최대한 높이기 위해서는 코어와 같은 속도로 동 작할 수 있는 고속의 메모리인 캐시와 레지스터가 필요하 다. 폰노이만 컴퓨터의 범용 레지스터는 1 개에 불과했지만 모토로라 6800(1974년)은 2개, 인텔 80386(1985년)은 8개, MIPS(1985년)는 32개, AMD64(2003년)는 16개의 범용 레지 스터를 포함하고 있다. 또한 컴파일러는 레지스터를 가급적 효과적으로 사용할 수 있는 기계어를 생성하기 위해 다양한 기법을 사용한다.

Patterson(2008)은 Hayes(1998)와 마찬가지로 중앙처리장 치를 데이터패스와 제어 장치로 구분하고 있다. Fig. 3은 Patterson(2008)에서 소개하고 있는 MIPS의 구조를 간략화 한 것이다. 그림과 같이 데이터패스는 명령어의 수행에 따 라 데이터의 연산 또는 데이터를 가지고 있는 부분으로 MIPS에서는 메모리(캐시), 레지스터, ALU, 가산기 등을 포 함한다. 즉, 현재의 중앙처리장치에서 데이터패스는 하나의 유닛을 의미하는 용어가 아니라 처리해야 할 데이터의 저장 및 데이터의 연산 등과 관련된 여러 유닛을 포함하는 용어 이다. 제어 장치는 명령어에 따라 데이터패스의 구성 요소, 주기억 장치, 입출력 장치 등의 동작 유형을 결정하는 신호 를 발생시키는 역할을 한다.

Patterson(2008)은 현재 전 세계 대부분의 대학에서 컴퓨 터 구조 과목의 전공 교재로 사용되고 있다. MIPS는 컴퓨 터를 이해하기 위해 필요한 중앙처리장치의 핵심적인 구성 요소들을 포함하고 있고 이해하기 쉬운 구조로 되어있기 때 문에 교육용으로 많이 활용되고 있다. 현재의 복잡해진 중 앙처리장치를 정확하게 이해하기 위해 간략화된 MIPS의 기

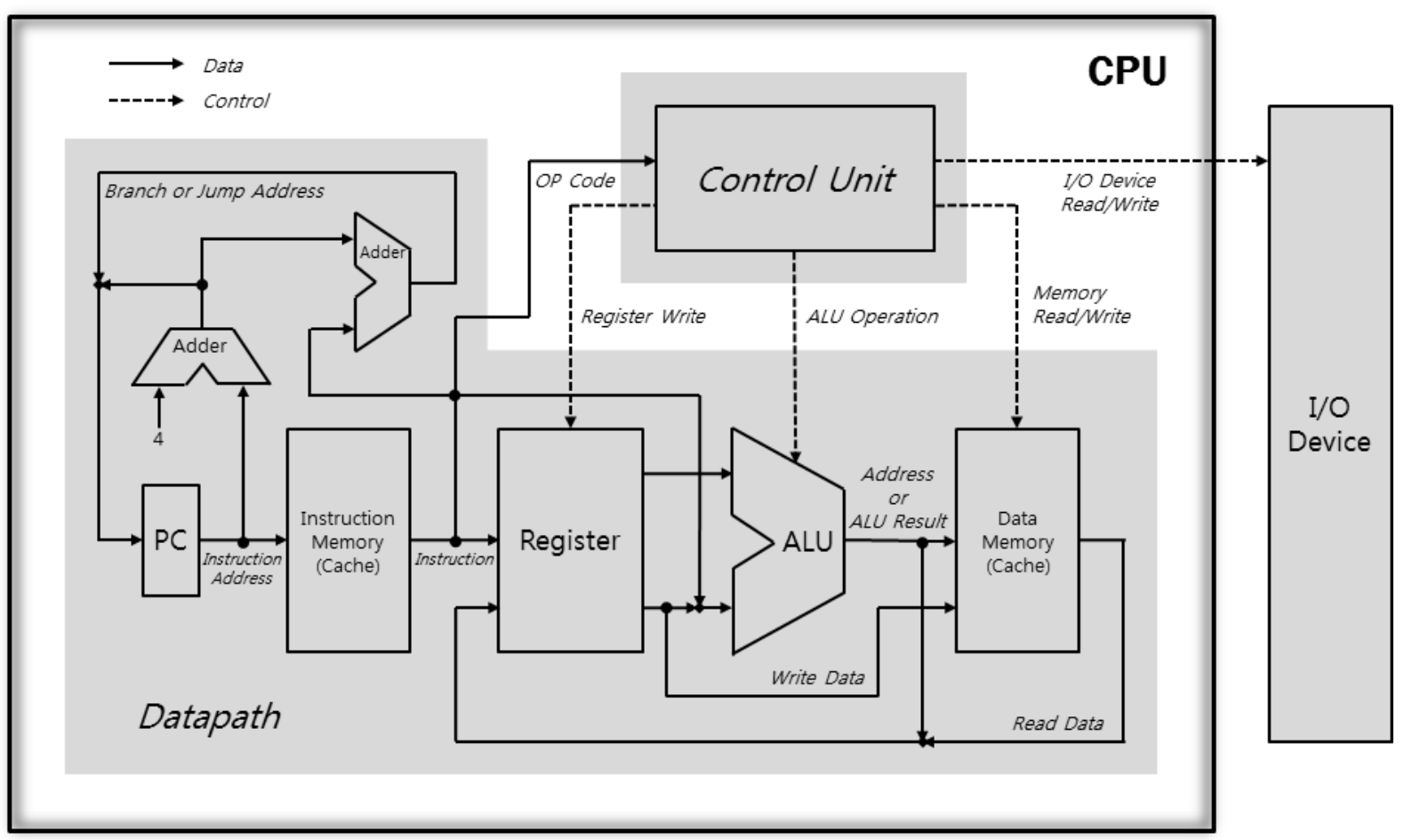

Fig. 3. Simplified MIPS CPU diagram 
본 구조 및 동작에 대해 분석을 하였다. 다음은 MIPS를 비 롯한 모든 중앙처리장치들이 프로그램의 수행을 위해 필수 적으로 지원하고 있는 기본 명령어들이다.

- 적재/저장 명령어: $\mathrm{lw}$ (load word), sw(store word)

- 산술/논리 명령어: add, sub, and, or

- 분기/점프 명령어: beq(branch if equal), j(jump)

중앙처리장치는 위의 기본 명령어들을 수행할 수 있도록 설 계되며 MIIPS의 경우 명령어의 수행이 다음과 같이 진행된다.

1. $P C$ 값을 사용하여 명령어를 인출하고, 제어 장치에서 명령어를 해석한다.

2. 점프 명령어를 제외한 모든 명령어는 레지스터를 읽은 후 $A L U$ 를 사용한다. 명령어별 $A L U$ 사용 목적은 다음 과 같다.

- 적재/저장 명령어 : 메모리 접근 주소계산

- 산술/논리 명령어 : 연산

- 분기 명령어 : 비교

3. 적재 명령어는 메모리 출력 값을 레지스터에 기록하고, 저장 명령어는 레지스터 출력 값을 메모리에 기록한다. 산술/논리 명령어는 $A L U$ 출력 값을 레지스터에 기록하 고, 분기 명령어는 비교 결과에 따라 $P C$ 값을 변경한다.

Table 3은 기본 명령어들 중에서 저장, 산술/논리, 점프 명령어 등을 수행할 때 사용하는 유닛들을 나타낸 것이다. 명령어별로 사용하는 유닛들의 조합은 서로 다르다. 저장

Table 3. CPU units utilized for instruction execution

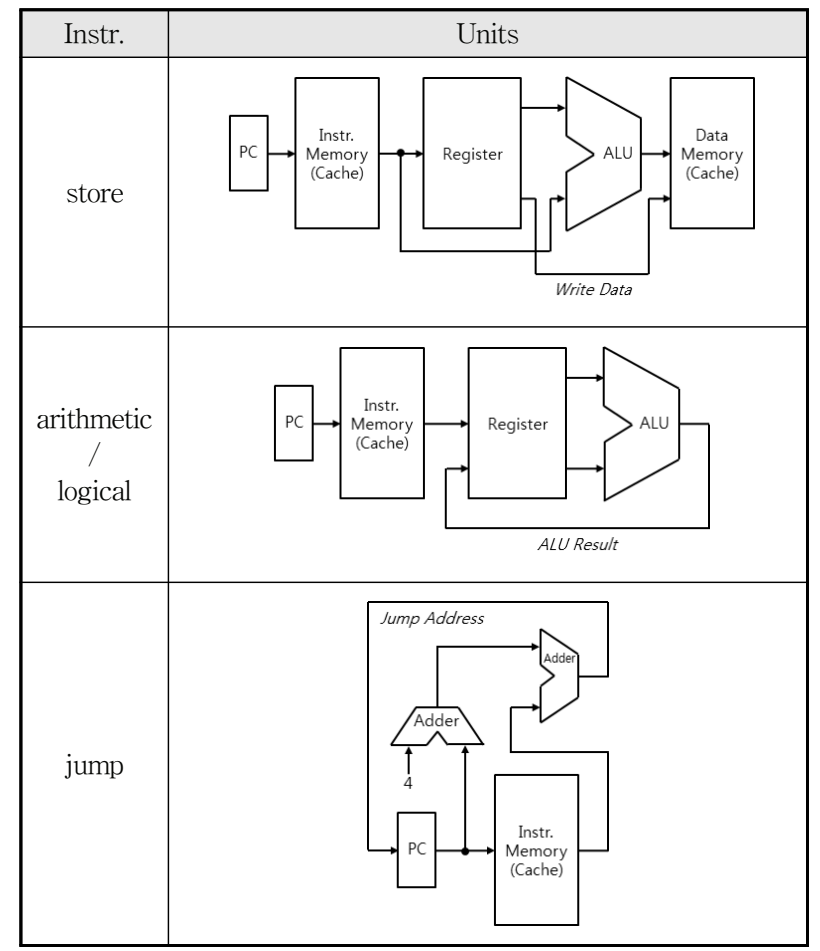

Table 4. Control signals for instruction execution

\begin{tabular}{|c|c|c|c|}
\hline \multirow{2}{*}{ Instr. } & \multicolumn{3}{|c|}{ Control signals } \\
\cline { 2 - 4 } & Register & ALU & Data Memory \\
\hline load & write & addition & read \\
\hline store & read & addition & write \\
\hline add & write & addition & $\times$ \\
\hline sub & write & subtraction & $\times$ \\
\hline and & write & and & $\times$ \\
\hline or & write & or & $\times$ \\
\hline branch & read & subtraction & $\times$ \\
\hline jump & $\times$ & $\times$ & $\times$ \\
\hline
\end{tabular}

명령어는 메모리, 레지스터 ALU를 모두 사용하지만 산술/ 논리 명령어는 데이터 메모리를 사용하지 않으며 점프 명령 어는 데이터 메모리, 레지스터, ALU를 사용하지 않는다. Fig. 3의 MIPS 구조는 프로그램의 실행에 필요한 기본 명 령어들을 수행하는데 있어서 ALU 외에도 메모리, 레지스터, 가산기 등이 반드시 필요하다는 것을 보여준다. 그리고 데 이터패스와 제어 장치는 시간적인 순서를 두고 독립적으로 동작하는 것이 아니라 명령어 인출 후 유기적으로 동작하게 된다. 즉, 제어 장치는 명령어를 해석한 후 데이터패스를 구 성하는 여러 유닛들의 동작 유형을 결정하는 신호를 생성한 다. 명령어에 따라 생성되는 데이터패스 유닛의 제어 신호 는 Table 4 와 같다.

\section{4. 개선 방안}

현재 데스크톱 및 노트북에서 주로 사용되고 있는 인텔 및 $\mathrm{AMD}$ 의 중앙처리장치는 명령어 길이가 다양하며 하나의 명령어가 많은 기능을 수행하는 CISC(Complex Instruction Set Computer) 구조를 가지고 있다. 그리고 중앙처리장치의 성능을 높이기 위해 명령어들 간에 의존성이 없을 때는 하 드웨어가 명령어의 순서를 바꾸어서 실행하는 복잡한 수퍼 스칼라(superscalar) 구조로 구현되고 있다. 하지만 중앙처리 장치 내부적으로는 $\mathrm{CISC}$ 명령어를 길이가 같은 마이크로코 드(ucode)로 변형하고, 이러한 마이크로코드의 처리량 (throughput)을 높이기 위해 파이프라인을 사용한다[20]. 파 이프라인의 모든 단계는 Fig. 3의 MIPS와 같은 기본 구조 로 간략화 될 수 있다. 현재 대부분의 스마트폰에 사용되고 있는 $\mathrm{ARM}$ 의 경우에도 파이프라인 기법을 적용하고 있으며 기본적인 구조는 Fig. 3의 MIPS와 크게 다르지 않다[21].

현재의 중앙처리장치는 초기의 컴퓨터와는 다르게 제어 장치와 연산 장치만으로 명령어의 실행을 설명하기에는 너 무 복잡해져 있다. 기본적인 명령어 수행을 위해 중앙처리 장치 내부에 반드시 존재해야 되는 유닛은 제어 장치를 비 롯하여 $\mathrm{ALU}$, 메모리, 레지스터, 가산기 등이 있다. 제어 장 치를 제외한 나머지 유닛들은 데이터의 연산과 저장 기능을 수행하는데, 현재 교과서와 같이 연산 장치(ALU)만을 언급 
하는 것은 비약적인 컴퓨터 하드웨어의 발전을 제대로 반영 하지 못한 결과이다.

따라서, 중앙처리장치는 현재의 컴퓨터 시스템을 적절히 반영하여 ‘데이터패스'와 ‘제어 장치'로 구분하는 것이 정확 한 표현이다. 데이터패스는 명령어에 따라 데이터의 연산하 고 또는 데이터를 일시적으로 저장하는 기능을 수행하는 부 분으로 메모리(캐시), 레지스터, $\mathrm{ALU}$, 가산기 등으로 구성된 다. 제어 장치는 명령어에 따라 데이터패스, 주기억 장치, 입 출력 장치 등의 동작 유형을 결정하는 부분이다. 또한 중앙 처리장치의 보다 정확한 이해를 위해 Table 4과 같은 데이 터패스와 제어 장치의 유기적 관계에 대한 설명을 포함하는 것이 바람직하다. 하지만 다소 생소한 전문 용어인 데이터 패스의 사용이 중·고등학교 학생들의 인지 발달 수준에서는 중앙처리장치를 쉽고 정확하게 이해하는데 오히려 방해가 될 수 있기 때문에 데이터패스의 특징과 의미를 잘 표현하 면서도 보다 이해하기 쉬운 일반적인 용어로 대체할 필요도 있다. 이에 본 연구에서는 데이터패스 대신 기존의 단어를 활용한 '연산 부분' 또는 '연산부’라는 표현을 사용하는 것이 바람직하다고 본다. 이 경우 특정한 하나의 장치를 의미하 는 제어 장치 또한 '제어 부분' 또는 '제어부’라고 표현하는 것이 의미적으로 적절한 용어이다.

\section{5. 결 론}

내실 있는 정보 교과서가 되기 위해서는 지적 발달을 자 극하고 촉구할 수 있는 컴퓨터 과학 분야의 핵심적인 내용 을 담고 있어야 하고 특히 최신 기술을 이해하기 쉽고 체계 적으로 반영해야 한다. 그러나 2007년 개정 교육과정에 따 른 중학교 정보 교과서에 기술된 중앙처리장치 관련 내용에 는 여러 가지 문제점이 발견된다. 중앙처리장치 구성 요소 의 설명이 교과서마다 상이하며 중앙처리장치 구성 요소 간 의 관계에 대한 설명이 부족하다. 이러한 이유로 인해 학습 자들은 중앙처리장치의 구조와 동작을 바르게 이해하는 데 어려움과 혼란을 겪을 수 있다.

본 연구는 현재 대부분의 대학에서 전공 교재로 사용되고 있는 컴퓨터 구조 전문 서적을 포함한 4종의 전문 서적 [13-16] 내용을 분석하여 정보 교과서에 나타난 문제점에 대한 원인을 파악하고 개선 방안을 제시하였다. 연구 결과 현재의 컴퓨터 시스템은 명령어의 수행을 위해 제어 장치와 연산 장치(ALU) 외에도 메모리, 레지스터, 가산기 등이 기 본적으로 필요하다. 따라서, 중앙처리장치는 Patterson(2008) 이 제시한 것처럼 데이터패스와 제어 장치로 구분하는 것이 정확한 표현이다. 또한, 중앙처리장치의 동작을 학습자가 보 다 정확하게 이해하기 위해서는 데이터패스와 제어 장치의 유기적 관계에 대한 설명을 포함하는 것이 바람직하다. 하 지만 학습자의 인지 발달 수준을 고려하지 않고 지나치게 어렵고 낮선 전문 용어를 사용하는 것은 바람직하지 않기 때문에 본 연구에서는 데이터패스 대신 '연산 부분' 또는 '연 산부', 제어 장치 대신 '제어 부분' 또는 '제어부'라는 용어를 사용할 것을 제안하였다.
2009년 개정 교육과정에서는 일반계 고등학교의 정보 교 과서에도 '컴퓨터의 구성과 동작' 영역이 포함된다[22]. 본 연구에서 제시한 개선 방안들이 새 교육과정에 따른 정보 교과서에는 바르고 일관성 있게 반영되어 학습자들이 컴퓨 터 시스템의 핵심 요소인 중앙처리장치의 구조와 동작을 정 확하고 쉽게 이해할 수 있게 되기를 기대한다.

\section{참 고 문 헌}

[1] Ministry of Culture and Education, The 286th Instruction by MCE [Separate Volume 4] Vocational High School Curriculum, 1971.

[2] Ministry of Culture and Education, The 88-7th Notification by MCE [Separate Volume 1] High School Curriculum, 1988.

[3] Ministry of Education \& Human Resources Development, The 2007-79th Notification by MEHRD [Separate Volume 10] Practical Course(Technology • Domestic Science) Curriculum, 2007.

[4] Ministry of Education \& Human Resources Development, The 2007-79th Notification by MEHRD [Separate Volume 16] Elective Subjects Curriculum of Middle School Discretion Activity, 2007.

[5] S. S. Kim, Y. S. KIM, Y. S. KIM, H. C. Yu, Y. J. Lee and E. K. Lee, Middle School Informatics1 authorized by MEST, Seoul: Kumsung Pub., 2011.

[6] T. W. Lee, W. K. Sim, S. C. Han, C. S. Lee, S. H. An, H. J. Choi and J. H. Park, Middle School Informatics1 authorized by MEST, Seoul: Doosan Dong-A, 2011.

[7] W. K. Lee, H. C. Kim, S. W. Yu, S. H. Lee, H. S. Han, E. M. Sin, T. W. Kim and J. H. Kim, Middle School Informatics1 authorized by MEST. Seoul: Mirae N, 2011.

[8] T. M. Jung, M. K. Oh, J. H. Park, S. B. Han and M. K. Kim, Middle School Informatics1 authorized by MEST, Seoul: Samyang Media, 2011.

[9] E. K. Hong and Y. J. Kim, Middle School Informatics1 authorized by MEST, Gyeonggi: Saengneung Pub., 2011.

[10] S. C. Kang, T. K. Kim, S. J. Je, N. H. Lee and S. Kim, Middle School Informatics1 authorized by MEST, Gyeonggi: Youngjin Media, 2011.

[11] S. M. Kang, J. A. Lee and I. H. Han, Middle School Informatics1 authorized by MEST, Seoul: Jihaksa Pub., 2011.

[12] M. K. Kim, H. R. Kweon, S. H. Choi and W. K. Tae, Middle School Informatics1 authorized by MEST, Seoul: Chunjae Education, 2011.

[13] J. P. Hayes, "Computer Architecture and Organization," McGraw-Hill, 1978.

[14] M. M. Mano, “Computer System Architecture," 3rd ed., Prentice Hall, 1993.

[15] J. P. Hayes, “Computer Architecture and Organization," 3rd ed., McGraw-Hill, 1998. 
[16] D. A. Patterson and J. L. Hennessy, "Computer Organization and Design," 4th ed., Morgan Kaufmann Pub, 2008.

[17] O. H. Kang and H. H. Song, "Analysis of Informatics-1 textbook based on Informatics Curriculum for Middle School Revised in 2007," The Journal of Korean Association of Computer Education, Vol.13, No.3, pp.35-45.

[18] S. W. Lee and T. W. Suh, "Problem Analysis and Recommendations of Memory Contents in High School Informatics Textbooks," The Journal of Korean Asscociatin of Computer Education, Vol.15, No.3, pp.37-47, 2012.

[19] S. W. Lee and T. W. Suh, "A Problem Study of Computer Systems Contents in Informatics Textbooks and National Technical Qualification Examination," in Proceedings of the KACE Summer Conference, Vol.16, No.2, pp.41-44, 2012.

[20] M. E. Thomadakis, "The Architecture of the Nehalem Processor and nehalem-EP SMP Platforms," Texas A\&M University, 2011.

[21] A. N. Sloss, D. Symes and C. Wright, "ARM System Developer's Guide," Morgan Kaufmann Publishers, 2004.

[22] Ministry of Education, Science and Technology, The 2011-361th Notification by MEST [Separate Volume 10] Practical Course(Technology • Domestic Science) Curriculum, 2011.

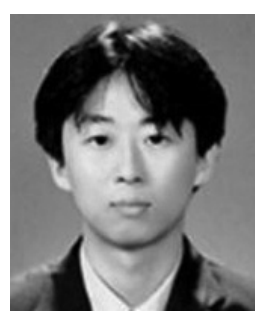

\section{이 상 욱}

e-mail : lesa@korea.ac.kr

2003년 경상대학교 컴퓨터교육과(이학사)

2011년 현 재 고려대학교 컴퓨터교육과 석사과정

2003년 2008년 백양고등학교 교사 2009년 현 재 가좌고등학교 교사

관심분야: 컴퓨터시스템, 컴퓨터교육

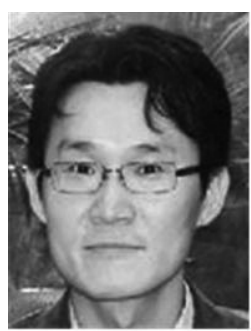

\section{서 태 원}

e-mail : suhtw@korea.ac.kr 1993년 고려대학교 전기공학과(공학사) 1995년 서울대학교 전자공학과(공학석사) 2006년 Georgia Institute of Technology Computer Engineering(공학박사) 1995년 1998년 LG종합기술원 주임연구원 1998년 2001년 하이닉스반도체 선임연구원 2004년 2006년 Intel Corp. Research Intern 2007년 2008년 Intel Corp. Systems Engineer 2008년 현 재 고려대학교 컴퓨터교육과 교수 관심분야: 컴퓨터구조, 임베디드시스템, 컴퓨터교육 